\title{
Madre coraje. La valentía vitalista de Ana Mae Barbosa
}

\author{
Ricard HUERTA. Universitat de València (España). ricard.huerta@uv.es
}

Esta entrevista a Ana Mae Barbosa fue realizada el martes 18 de agosto de 2015. Las fotografías que acompañan al texto fueron tomadas por Germán Navarro Espinach. Ubicados en la casa de Sao Paulo de la arte/educadora (concepto que ella defiende), la conversación se inició a las seis de la tarde y duró más de tres horas, durante las cuales, además de contestar a las cuestiones planteadas, Ana Mae nos fue explicando cada uno de los objetos (la mayoría de ellos obras de arte) que se pueden ver en las paredes y estanterías de los diferentes espacios de la vivienda. En una de las habitaciones está su hija Ana Amália Barbosa, también educadora de arte, quien desde 2002, y como secuela de un accidente vascular cerebral, quedó tetrapléjica y muda, pero consciente y con una capacidad cognitiva preservada por entero (véase la reseña de Germán Navarro de su libro Além do Corpo: Uma Experiênciaem Arte-Educaçao, en Arterapia, vol. 10, 2015, pp. 351-353). Además de conversar con la madre y la hija, pudimos conocer a Ana Lía, la nieta adolescente de Ana Mae, e hija de Ana Amália. Tres generaciones de mujeres valientes y luchadoras. Este documento sirve de homenaje y celebración de los 80 años de Ana Mae. Nos sumamos así a tantos otros actos organizados durante 2016, entre los que destaca su nombramiento como Doctora Honoris Causa por la Universidade Federal da Paraíba, así como los innumerables congresos y eventos en los que se le ha rendido tributo.

RH: Para mí es un gran honor entrevistarte ¿Cómo vive el hecho de ser una de las personalidades más importantes en el panorama internacional de la Educación Artística?

AMB: Eso es porque usted me considera así. Pero lo cierto es que los problemas de la Educación Artística en Brasil son enormes, y hemos tenido que luchar durante mucho tiempo, de manera que no me considero eso, sino más bien una luchadora. Una luchadora por los derechos de los más pequeños y de los jóvenes, teniendo en cuenta que la educación en artes es algo importante para la formación de la 
conciencia humana. Si tuviese que elegir una palabra sería militante. Soy una militante de la arte/educación. Cuando empecé no había tradición al respecto, y de hecho fui la primera doctora en arte/educación del Brasil. Hice de todo, trabajar en museos, trabajar en el taller del museo estudiando las metodologías de la enseñanza del arte e incluso de la historia de la Educación Artística. He tenido la necesidad de trabajar en todas las ramas relacionadas con la Educación Artística, vinculándola con el resto de las áreas. En aquel momento no era una cosa tan común como lo pueda ser ahora. En la actualidad las personas se pueden especializar, desde muy temprano, en algún tema concreto, en los masters universitarios, en sus doctorados, trabajando más profundamente en una cuestión concreta sin tener que abarcar todas las áreas, como tuvimos que hacer los que iniciamos esta tradición.

\section{RH: Defiendes la historia como una de las claves para mirar hacia el futuro ¿Por qué piensas que no se le da la importancia que merece a la historia de la Educación Artística?}

AMB: Es una cuestión complicada. Realmente no sé por qué se da ese desprecio hacia la historia. En general, en todo nuestro continente, incluso en los países del norte de América, se evidencia ese desprecio por la historia de la Educación Artística. Pienso que tal vez es el resultado de un ideario modernista de transformación, como si no se pudiese hacer transformación valorando la historia. La idea de que el arte debe ser algo completamente nuevo, sin vínculos con la tradición, rompiendo con el pasado, coincide con el planteamiento modernista, al contrario de lo que sucede con el posmodernismo, en donde se valoran los referentes anteriores. También porque mi planteamiento de la historia es situado. Lo que estamos haciendo nosotros aquí en este momento, dentro de unas horas será historia. Tengo un concepto más contemporáneo de la historia, que es lo que ocurre, algo que se puede analizar e interpretar... E imaginar. Para mí, historia e imaginación van unidas. El presente pasa demasiado rápido, al momento ya es pasado.

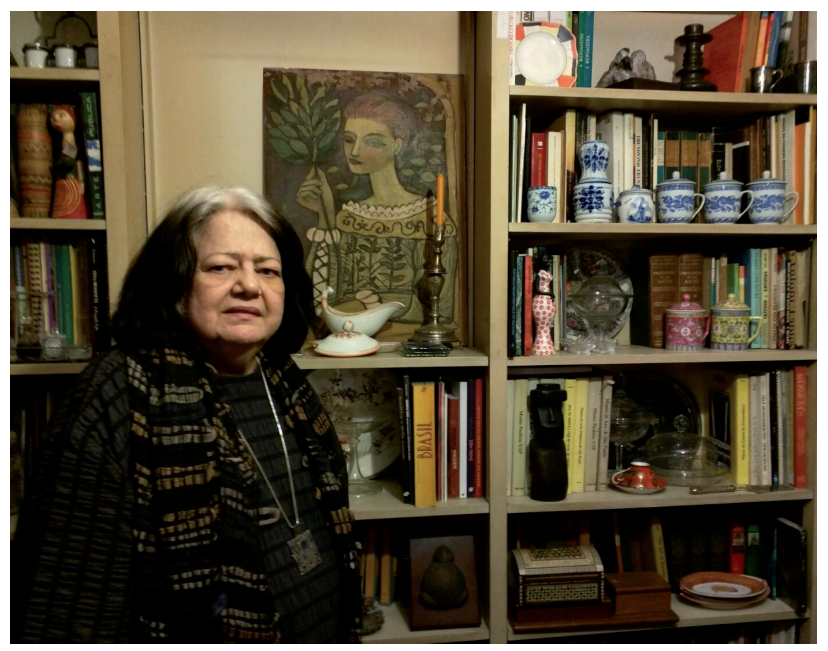

Figura 1. Ana Mae Barbosa junto a objetos y libros que conserva en el salón de su casa. 


\section{RH: Supongo que la clave de nuestra presencia en el mundo sigue siendo InSEA, organización de la que fuiste presidenta mundial.}

AMB: Pienso que sí. Pero en cualquier caso la necesidad que plantea InSEA de abarcar todo el mundo, con tantos países diferentes, en realidad es un poco conservadora. Fue durante las presidencias de Marie-Françoise Chavanne (19851988), ElliotEisner (1988-1991) y la mía (1991-1993) cuando intentamos cambiar un poco el conservadurismo de las estrategias de InSEA, y pienso que hoy es una organización mucho más abierta. Hay menos reglas que seguir, incluso ahora existen más puestos para representantes regionales. Yo trabajé más de 20 años en InSEA, pero nunca convoqué aquí un congreso con las siglas InSEA, porque las exigencias eran tantas que resultaba difícil cumplirlas siendo de un país en desarrollo como Brasil. Trabajábamos los congresos con ayuda del Estado, pero había una regla de InSEA que decía que el 10\% del presupuesto del congreso debía ser par InSEA, algo completamente imposible para nosotros con el dinero estatal. Un problema de InSEA es que todavía no reconoce plenamente el CLEA, el Comité Latinoamericano de Educación por el Arte, creado en 1984. Todo depende del empeño de quien preside y de los representantes de cada región. Los países latinoamericanos son extremadamente multiculturales, porque ya había culturas anteriores a la invasión, la colonización, la ocupación. La tensión entre la cultura de los colonizadores y las culturas indígenas autóctonas perdura hasta hoy. Por tanto, es necesario tener una política propia. No es fácil hacer una política particular de cada país dentro de una organización que lo abarca todo. Nosotros continuamos resistentes ante el colonialismo, como pasa ahora con los Estados Unidos. Para mí es importante el diálogo, pero yo quiero poder escoger con quién dialogo, y poder lanzar diferentes diálogos en función de con quien lo haces. Resulta pernicioso para un país seguir solamente lo que marca una universidad extranjera.

RH: En el panorama americano, y sobre todo en el brasileño, se ha insistido en el término arte/educación y en la función de los arte/educadores. ¿Cómo encaja esta mirada en relación con lo que ocurre en otras partes del mundo?

AMB: Yo misma fui la creadora del término arte/educación. La artista norteamericana Margaret Spencer fundó junto al brasileño Augusto Rodrigues la primera Escolinha brasileña. Llegaron a ser más de 130 escolinhas de arte. Promovían la educación fuera de la escuela. Según Spencer, Brasil no debía copiar ningún sistema educativo exterior, sino que debía crear el suyo propio. En vez de la traducción literal del inglés Art Education, opté por el término "arte/educación". Tras realizar mi doctorado, estábamos muy implicados en la lucha por la democracia en Brasil; vivíamos en una dictadura militar, donde los de educación rechazaban el arte porque era muy peligroso, y los de arte rechazaban la educación, por ser de derechas y conformista. Primero usábamos la separación con guion central (arte-educaçao), pero por consejos lingüísticos preferimos con barra de separación: arte/educaçao. 


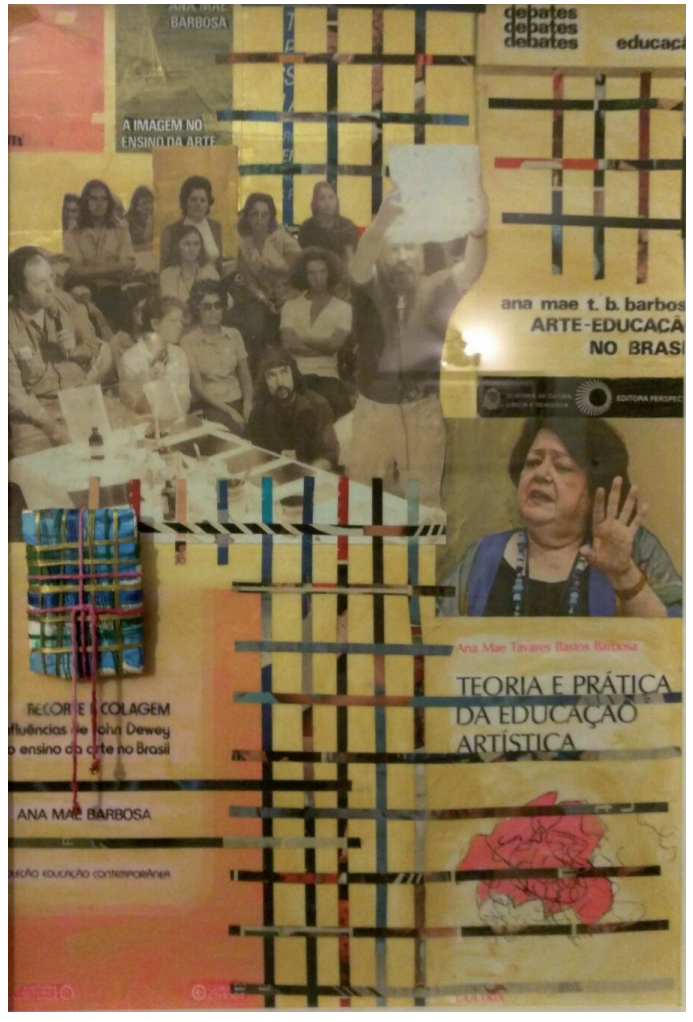

Figura 2. Collage alegórico dedicado a Ana Mae realizado por un amigo artista.

RH: Tu tesis doctoral defendida en la Universidad de Boston en 1979 lleva por título American influences on Art Education in Brazil: analyses of two moments: Walter Smith and John Dewey. Dewey sigue siendo una pieza clave en la educación en nuestros días, al igual que Paulo Freire, con quien trabajaste. ¿Por qué es tan necesario tratar los temas educativos desde una perspectiva social?

AMB: Quisiera hacer una relación entre John Dewey, Paulo Freire y ElliotEisner. Ellos no estaban en desacuerdo conmigo, pero me falta tiempo para explicar detenidamente mi posicionamiento en relación con sus teorías. Está entre mis perspectivas hacerlo, eso sí. Algún día trabajaré la relación entre estos tres autores, ya que es importante.

RH: En tu libro Redesenhando o Desenho: educadores, política e história (Cortez Editora, 2015) insistes en que las luchas internas entre tendencias universitarias paralizan muchas posibilidades de ampliar la presencia de la educación artística.

AMB: Son únicamente relaciones de poder, pero ¿de qué poder hablamos? El poder de la universidad es fatuo, en realidad tiene poca importancia, ya que es leve.

RH: ¿Se puede enseñar el oficio de tipógrafo a quien desconoce el alfabeto? Es una reflexión escrita por Theodoro Braga en 1923, hace casi un siglo. 
AMB: Completamente imposible. Sé que hoy existe una reacción generalizada contra la alfabetización visual. Para mi alfabetización no es una cosa mecánica. Yo tengo el concepto de Freire: dar cuenta del mundo, de lo que acontece; por eso creo que la alfabetización visual es algo importante. $\mathrm{Y}$ en todas las profesiones: desde el hombre que pasa nuestras maletas en el registro del aeropuerto, hasta el médico, que debe saber leer unos rayos x. Resulta necesaria la alfabetización para una lectura de la imagen.

\section{RH: Cecília Meireles luchó por los derechos de las mujeres y por la educación artística en Brasil e Iberoamérica ¿Te sientes muy identificada con ella?}

AMB: Existen coincidencias. Cecilia perdió a sus padres con seis años de edad. Yo perdí a mi madre con tres años, a mi padre con seis. Me crie con la madre de mi madre. Meireles habla de una infancia muy solitaria, que yo también tuve, con la compañía de mis libros. Mi madre no quería que yo aprendiese a leer muy temprano. Estaba en contra de que se enseñase a leer y escribir a los niños antes de los cinco años. Lo que debían hacer era jugar. Mi abuela siguió esta idea de mi madre, y yo a los siete años todavía no sabía leer. Mi primer acceso a la escuela fue a los siete años; el resto de mis compañeros ya sabían leer. Mi abuelo tenía una biblioteca fantástica; era el lugar de la casa que más me gustaba; pasaba horas allí mirando los libros; creo que en realidad yo estaba leyendo, aunque era el gran deseo de leer lo que primaba, y el contacto con los libros. Tenía los libros como compañía. La soledad de la que habla Cecília era más entristecedora que la mía.

\section{RH: Ella y tú coincidís también al haber luchado en territorio de hombres. Tú fuiste incluso directora del MAC (Museo de Arte Contemporáneo) de la USP (Universidad de São Paulo).}

AMB: Tengo pocos enemigos, y entre ellos solamente una mujer, que es medio enemiga, si bien su enemistadno es completamente declarada. El resto son hombres; es muy curioso. En general se trata de hombres que desean mucho el poder. Tengo grandes amigos hombres, poderosos y no tanto. Estuve casada 47 años con el mismo hombre, y con la mayoría de alumnos y compañeros profesores mantengo amistad. En el área de Educación Artística en Brasil hay pocos hombres, pero suelen tener deseo de figurar. 


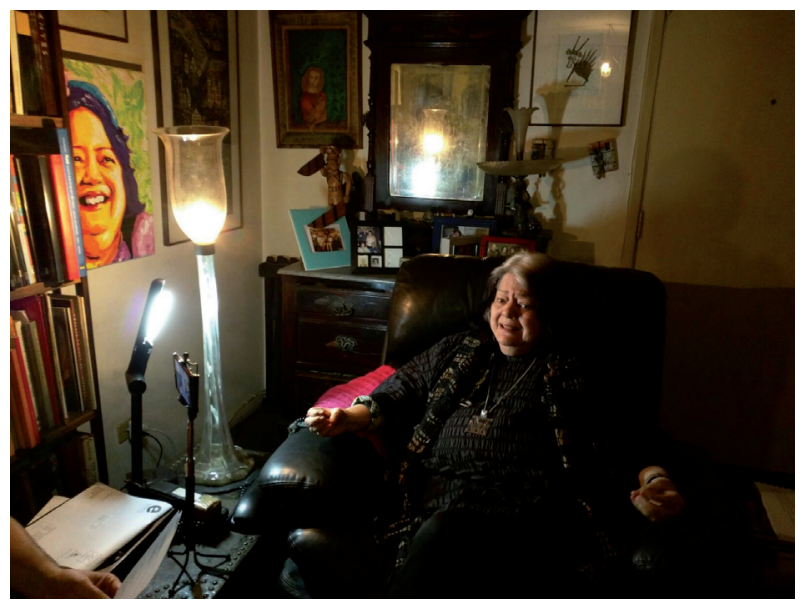

Figura 3. Ana Mae Barbosa durante la entrevista realizada en su casa.

\section{RH: ¿Qué es más difícil negociar con artistas o negociar con arte/educadores?}

AMB: Para mí es mucho más difícil negociar con la burguesía que tiene el poder sobre el arte. Cuando fui directora del MAC el diálogo con los artistas era excelente. Las producciones y exposiciones del museo eran dialogadas con los artistas. Era fácil dialogar con ellos. Los arte/educadores son en Brasil el tipo de profesorado más receptivo a los cambios. La FAPESP, una importante fundación de investigación, con buen presupuesto, optó hace seis años por financiar proyectos que uniesen la universidad con la escuela. Conversé con muchas personas que llevaban a cabo estos proyectos, y declaraban que la mejor recepción que habían tenido era la de los profesores de arte, siempre los primeros dispuestos a colaborar con los cambios, y los últimos en desistir.

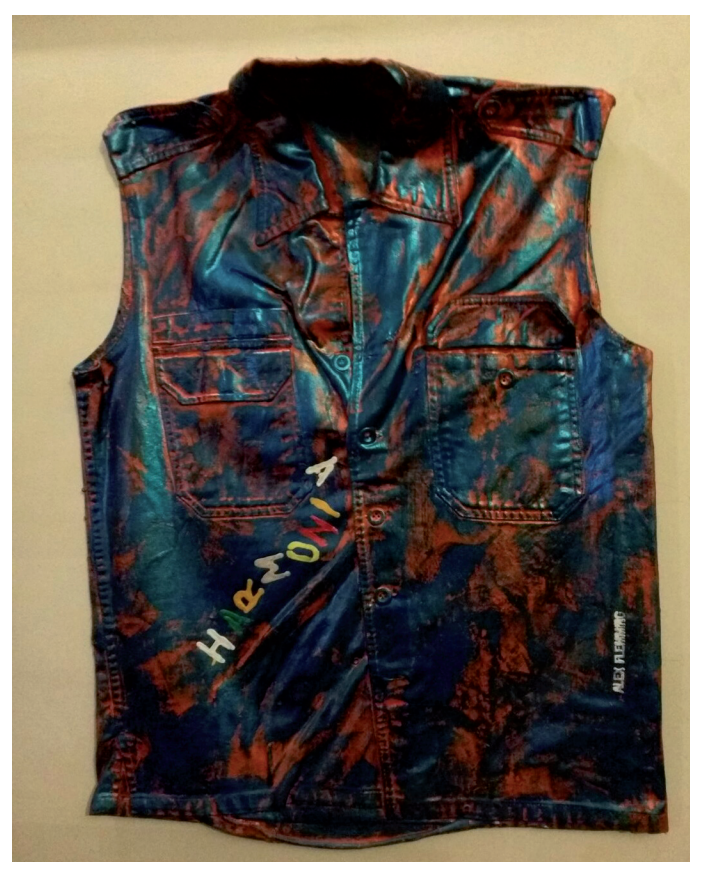

Figura 4. Obra del artista Alex Flemming, pieza expuesta en una de las paredes de la casa. 
RH: ¿Por qué quienes nos situamos en el territorio de la Educación Artística seguimos siendo vistos como profesionales poco valorados?

AMB: Nuestro poder es aceptar la marginalidad, eso es importante. En ese momento nos empoderamos. De ese modo podremos cambiar algo.

RH: Existe una rica tradición en Iberoamérica que pasa por nombres tan señalados como Gerardo Seguel, Adolfo Best Maugard, Elena Izcue, Manuel Pantigoso, Luis Errázuriz, Salomón Aznar, Ramón Cabrera, Olga Olaya, Lucía Pimentel, o tú misma. ¿Esto significa que se ha trabajado bien?

AMB: Es necesario investigar el pasado de América latina, porque es importante. En México olvidaron hermosos proyectos que hubo, como las Escuelas al Aire Libre, que yo las considero pioneras del muralismo. Uruguay tiene una buena tradición. También Argentina, con las pioneras Olga y Leticia Cossettini, ambas expulsadas de la escuela que dirigían, pero que ahora son más visibles gracias al trabajo de un solvente grupo de investigación de Rosario. Incluso en Chile existe buena tradición. En Brasil tenemos que resolver un problema: hablamos de arte/educación como de un gran paraguas donde todo cabe, tanto para desarrollar la capacidad de las personas al acercarse al arte como para crear maestrías y doctorados en la universidad. Luis Camnitzer eleva una pregunta muy curiosa: ¿Será que estamos haciendo enseñanza del arte?, desconfiando de la validez de la palabra enseñanza. Lo que deseamos en realidad es contaminar con el arte a los jóvenes, ya que queremos que ellos consideren el arte como algo importante para sus vidas, porque "es" algo importante, en todos los sentidos. Arte, para mí, era siempre excitación. Yo desconocía la parte de apaciguamiento del arte. Cuando mi marido estuvo cuatro meses en el hospital, antes de morir, la única cosa que yo deseaba al salir de allí era ir a ver una exposición. Y descubrí algo muy curioso: que soy una apasionada del arte digital. Pero no me apaciguaba el arte digital. Lo que más me calmaba era el grabado en madera, no sabría explicar por qué. Había por entonces una exposición de xilografías, a la que fui varias veces: me reconfortaba.

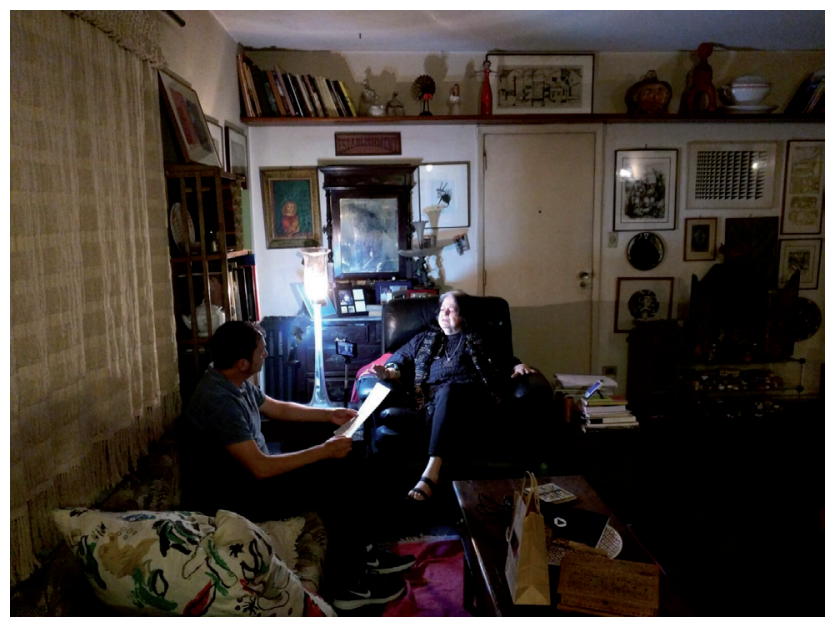

Figura 5. Otro momento de la entrevista a Ana Mae Barbosa. 
RH: Hablas del dibujo como práctica esencial, y defiendes el grafismo para realizar imágenes, ya que según tu concepto de la "triangulación", siempre debe haber una parte práctica.

AMB: Está muy ligada con la lectura de la imagen, pero siempre debe haber una práctica. El profesorado debe encontrar el lugar para que encajen la lectura, la realización y la parte de sentido de arte en su contexto, ya que muchas veces para dar sentido a estas imágenes se han de provocar nuevas recepciones de la obra. A mi entender, el contexto es algo importantísimo. A través del contexto abrimos las puertas a otras disciplinas, y abrimos las puertas a problematizaciones más complejas, donde exista la participación de diferentes campos de saber. Desde el punto de vista social, la contextualización permite observar el punto de vista de la clase dominante, que es la que decide el tipo de educación del país. Es importante sentir que tu cultura de origen es reconocida. Todo ello forma parte del contexto.

\section{RH: Estás muy impregnada de la Arts Based Research, hasta el extremo de que} en tus trabajos escritos utilizas los textos de autores como si fuesen imágenes.

AMB: La tipografía de los antiguos periódicos, la caligrafía de las personas, son elementos visuales que me interesan. Las cartas de una historiadora del arte a una arte/educadora es un documento magnífico, asociado a la caligrafía y relacionado con los ideales de aquel momento, Entonces era importante tener una buena caligrafía. Los papeles de carta timbrados de los hoteles, todo ello forma parte de la imagen de la carta. No las reproduzco tanto para que se lea la carta, sino para que se vea como imagen

\section{RH: Tu libro Redesenhando o Desenho tiene bastante de narración autobiográfica ("minha solidãofoi sem drama, imaginativa, cercada de animais"). Las cuestiones personales impregnan la trayectoria profesional. ¿Qué cosas destacas como importantes ahora en tu vida?}

AMB: Siempre ha resultado muy difícil para mí equilibrar la vida personal y la profesional. Fui la primera mujer universitaria en mi familia, donde los hombres habían estudiado desde el siglo XVIII, cuando marchaban a Portugal para estudiar. Tuve una discusión muy fuerte con mi abuela, porque no quería que yo estudiase en la universidad. No conseguí el apoyo de ningún hombre de mi familia, y para ir tuve que luchar sola. Yo quería estudiar Medicina para hacer Psiquiatría, pero en esa época había muy pocas mujeres en la Facultad de Medicina. Tuve que optar por Derecho, descartando Medicina porque mi abuela no me dejaba, y eliminando Ingeniería, la otra carrera de prestigio por entonces, porque siempre he odiado las matemáticas. En el primer año, entre los doscientos alumnos de Derecho había solamente ocho mujeres. El machismo ha sido la peor experiencia educacional de toda mi vida. En el examen de acceso fui la segunda clasificada. Me enamoré de mi marido en el primer curso de Derecho, y nos casamos en el cuarto año de carrera. El quinto año estaba embarazada, y entramos a un examen oral de una disciplina, mi marido, un amigo y yo. Los exámenes orales eran dramáticos. Se celebraban en un 
auditorio, un anfiteatro lleno de compañeros que observaban. Por mi apellido, yo era la primera, y respondí largo y tendido a una pregunta que salía al azar. Hablé tanto porque había estudiado mucho. Un miembro del tribunal se dirigió a mi marido y le dijo, con tono despectivo: "Usted ha instruido (enseñado) muy bien a su patrona (su mujer)". Cuando intervino mi marido no estuvo muy acertado al contestar a la pregunta que le tocó. El jurado le preguntó: “¿Qué puntuación necesita para pasar?” Él contestó: "Con un cinco va bien". En ese momento podrían haber aprovechado para enmendar el error y la actitud impropia que habían tenido conmigo, pero no dijeron nada. En ese momento opté por abandonar los estudios de Derecho. Fue mi última experiencia en la Facultad de Derecho, donde pensaban que el hombre sabe más que la mujer. En relación con los hijos siempre fue difícil equilibrar. Solo pude ser profesora a tiempo completo después de que mis hijos creciesen. Actualmente mi prioridad es mi hija. Mis coordinadores de la universidad respetan esto. Mi hija es tetrapléjica y necesita cuidados especiales, por eso sigo intentando equilibrar mi vida profesional con mi vida en casa. La decisión fue dotarle de la mayor independencia posible, adecuando una habitación de la casa, haciéndola partícipe de cuándo debe tomar sus medicamentos. Pero yo quiero estar muy pendiente, porque ella es mi prioridad.

\section{RH: Una pregunta sencilla para terminar. ¿Cuál es tu película preferida?}

AMB (riendo): Casablanca. 